\title{
Equivalence between invariant measures and statistical solutions for the 2D non-autonomous magneto-micropolar fluid equations
}

\author{
Yanjiao $\mathrm{Li}^{1}$ and Xiaojun $\mathrm{Li}^{1}$ \\ ${ }^{1}$ Hohai University
}

June 8, 2021

\begin{abstract}
In this article, we aim to investigate the regularity of statistical solution for the $2 \mathrm{D}$ non-autonomous magneto-micropolar fluid equations as well as the relationship between invariant measures and statistical solutions. Firstly, to get the regularity of the statistical solution, we prove the existence and regularity of the pullback attractor for the equations. Then we prove the statistical solution possesses some regularity properties by using regularity of the pullback attractor. Finally, we prove the statistical solution is actual an invariant measure for the equations.
\end{abstract}

\section{Hosted file}

Equivalence between invariant measures and statistical solutions for the 2D non-autonomous magneto-micr available at https://authorea.com/users/418613/articles/525304-equivalence-betweeninvariant-measures-and-statistical-solutions-for-the-2d-non-autonomous-magnetomicropolar-fluid-equations

\section{Hosted file}

Equivalence between invariant measures and statistical solutions for the 2D non-autonomous magneto-micr available at https://authorea.com/users/418613/articles/525304-equivalence-betweeninvariant-measures-and-statistical-solutions-for-the-2d-non-autonomous-magnetomicropolar-fluid-equations 